\title{
VAT And Electronic Books
}

Raquel Álamo Cerrillo, University of Castilla-La Mancha, Spain

Ma Gabriela Lagos Rodríguez, University of Castilla-La Mancha, Spain

\begin{abstract}
The publishing sector has experienced an important change linked to the emergence of electronics books. This new reality has an impact in the cultural industry and demands the adaptation of public regulations that affect the production and consumption of cultural goods and services. For this purpose, the authors carry out an analysis of the legislation applicable to the cultural sector, focusing on the publication of electronic books, in order to meet the impact of these measures in the economy.
\end{abstract}

The importance of public action is made clear in the protection of copyright and the fight against illegal access, in order not to reduce tax collection, because this could be negative for the support of the worselfare state.

The analysis is carried out for the Spanish case, although the results obtained may be extrapolated to the rest of the states of the European Union, given that the regulations are community-based.

Keywords: VAT; Electronic Books; Tax Collection; Sufficiency; Neutrality; Culture

\section{INTRODUCTION}

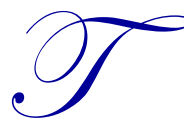

he provision of electronic books has experienced an important transformation since the last decade of the twentieth century as a consequence of the spread of information and communication technologies. The growing presence of intangible books, those that can do without a physical medium and can be distributed in full online, means significant changes in access to culture, which impact on the industry that supplies it and demand the adaptation of the public regulations that affect its production and consumption.

The possibility of doing without the physical market implies substantial changes in the essential elements of exchange from prices to the medium of dissemination and the range of the latter, for example. In contrast, the growing accessibility of the Web has facilitated its fraudulent use, generating one of the most serious problems in the cultural sector today, which is no other than the illegal consumption of electronic books. This problem is global due to both the open character of the Internet and the economy and culture. States have reacted, modifying and reinforcing legislation on copyright protection and penalizing access and illegal downloads. However, the consumers' opportunistic behavior not only affects the authors or the cultural industry, but also has consequences for the public purse, meaning an important loss in fiscal resources.

With this in mind, the authors intend to analyze the fiscal repercussions of the increase in the consumption of electronic books in Spain. Moreover, it offers us an unbeatable example of the impact of the appearance of digital goods and services on the tax system, given that the authors can differentiate the treatment they are given in comparison to those which have a physical medium. This question is no less important in the field of Public Treasury, since one of the basic principles of tax regulation demands ensuring the neutrality of tax treatment. In other words, tax intervention should not alter the economic decisions of private agents in the production and consumption of goods and services. When these decisions are oriented towards obtaining a tax advantage, the efficiency of the system, as a whole, is compromised and the affected sector in particular. The consequences are so serious that a mere tax collection motive cannot justify tax measures that are not neutral. 
To finish, the authors will present the main conclusions extracted from the elaboration of this document, with the aim of satisfying the objective of discovering the fiscal repercussions of the increase in e-book consumption.

\section{ELECTRONIC BOOKS AND TYPES OF VAT}

In general, all of the final goods and services distributed in the European Union, and therefore in Spain, are subject to VAT. Looking at the tax rate applied to commercial operations subject to this tax, the normal VAT rate is fixed at a percentage of the tax base that can be no less than 15\%, until the $31^{\text {st }}$ of December 2015. Although, Member States can apply one or two reduced rates to those deliveries of goods and services gathered in the III Annex of the VAT Directive, among which the authors find goods and services of a cultural nature, like paper books. The objective pursued, with the permission of reduced tax rates for goods and services of a cultural nature, is to facilitate simpler and cheaper access to these goods and services for citizens.

The Sixth VAT Directive allows the application of reduced rates to books to facilitate citizens' access to them. In the legislative text, the supply of books is mentioned without distinguishing between books in print format and electronic books. Therefore, from a literal interpretation of this, the authors could consider that, in both cases, it would be appropriate, on the part of the Member States, to apply a reduced VAT rate, given that regardless of the format, in both cases, a book is being acquired. In the case of Spain, for example, the super-reduced rate of $4 \%$ would be applied. However, this is not the case, since the super-reduced rate is applied only to books in print format, and electronic books, on the contrary, have to pay the general rate (21\% in the case of Spain) there being, thus, negative tax discrimination for electronic books. The regulations regarding VAT are applicable in all of the European Union territory, which means that the tax discrimination existing between traditional books and electronic books is found in all Member States.

From a general standpoint, it is considered in the European institutions that the treatment of cultural VAT should be uniform across the Member States. This stance responds not only to the objective of tax harmonization desired by the Union or to the undeniable advantages it would have in terms of interior market functioning, but underlies an important concern which is no other than to protect and favor the European cultural industry from the pressure of other global competitors, especially in the field of the production and dissemination of cultural materials online. Already in 2011, the European Parliament's Committee on Culture and Education made a request aiming to harmonize and favorably treat the VAT of cultural goods and services and, coinciding with this stance, the European Commission worked on a proposal for the harmonization of the tax that foresaw a general application of reduced rates in this sector.

In line with the above, it could be supposed that this foreseen favorable treatment would also include electronic books. However, their tax treatment presents an important specification which justifies the current situation and which implicates their future treatment. The European Commission has established that for the classification of commercial operations that are developed in the European Union territory, commercial transactions carried out through direct electronic commerce will be classified as services provision, while operations of indirect electronic commerce will be classified as delivery of goods. That is, the purchase of a book in print format is considered as delivery of goods, while electronic books, direct substitutes of the former, will be considered as services provision.

The reason for this difference in classification is found in the important development of e-commerce in recent years and the generalization and increase in sales of intangible goods (among which the authors find electronic books). This motivated the EU in 2002 to carry out an adaptation of the VAT regulations for the new commercial reality ${ }^{1}$, in such a way that, as the authors have indicated, electronic books are not classified as delivery of goods (as is the case of traditional books), but as services provision, on the basis that they lack a material physical medium.

\footnotetext{
${ }^{1}$ Council Directive 2002/38/EC of 7th of May 2002, by which the Directive 77/388/EEC is modified in relation to the value-added tax system applicable to broadcasting and television and other services provided electronically.
} 
To the problem of double classification according to the good's format, the authors must add the difficulty of determining the place where the commercial operations are carried out. The general rule for establishing the place of development of a taxable transaction varies according to whether the authors are dealing with delivery of goods or provision of services. In the first case, the rule to follow is taxation at destination, while for services provision, the principle of taxation at source ${ }^{2}$ is followed. This situation caused a loss in Europe's competitiveness in ecommerce seen as if the service or good was provided by a company established in the EU it was taxed, whereas if it was provided by an entity not established in this territory, it was not affected by VAT. With the aim of resolving this problem, the tax legislation is modified and the final result is as shown in Figure 1.



Source: Own Elaboration

Figure 1: Taxation Of Books Through VAT

E-books, therefore, are first considered as services provision. Secondly, as they are intangible goods, they are taxed according to the special location rule, valid for direct e-commerce; that is, at destination or at source, depending on the condition of the beneficiary.

The authors need to look closely at this difference of treatment, based on mere variety in the good's medium and which is not easily arguable without considering the technical elements of the tax. Thus, it seems undeniable that whether it is a file or a printed book, the content and the function it serves will be the same, leaving without justification this discriminatory treatment. In the authors' opinions, what underlies and explains this decision of the Council is the will to ensure that the countries producing these intangible goods receive payment of the operation's tax charge, especially if this is carried out with countries not producing these intangible goods. Without delving too deep into the configuration of the VAT, the authors should indeed remember that a transitional VAT system at destination is still in force, which should be substituted by the system of VAT payment at source.

As can be observed in Table 1, the differences in tax rates between a traditional book and an electronic book are very important. The state in which the authors find the greatest difference is Ireland, where printed books have a zero tax rate, while e-books pay $23 \%$ tax. In the case of the United Kingdom, electronic books have a $20 \%$ rate, while traditional books do not pay taxes. It is also worth pointing out the case of Luxemburg, where both types of books pay 3\%, and France, where electronic books pay only 7\%, with the greater tax rate being applied to traditional books, at $19.6 \%$. In general, in all of the Member States there is an important difference between the taxation of electronic books and traditional books.

\footnotetext{
${ }^{2}$ The place of realisation of goods deliveries is regulated in article 8 of the Sixth Directive.
} 
Table 1: Traditional Books Vs. Electronic Books

\begin{tabular}{|c|c|c|}
\hline & Tradicional & Electrónico \\
\hline Belgium & 6 & 21 \\
\hline Bulgaria & 20 & 20 \\
\hline Czech Republic & 15 & 21 \\
\hline Denmark & 25 & 25 \\
\hline Germany & 7 & 19 \\
\hline Estonia & 9 & 20 \\
\hline Greece & 6,5 & 23 \\
\hline Spain & $4 / 21$ & 21 \\
\hline France & $5,5 / 19,6$ & 7 \\
\hline Ireland & 0 & 23 \\
\hline Italy & 4 & 21 \\
\hline Cyprus & 5 & 18 \\
\hline Letonia & 12 & 21 \\
\hline Lithuania & 9 & 21 \\
\hline Luxembourg & 3 & 3 \\
\hline Hungary & 5 & 27 \\
\hline Malta & 5 & 18 \\
\hline Netherlands & 6 & 21 \\
\hline Austria & 10 & 20 \\
\hline Poland & 5 & 23 \\
\hline Portugal & 6 & 23 \\
\hline Romania & 9 & 24 \\
\hline Slovenia & 8,5 & 20 \\
\hline Slovakia & 10 & 20 \\
\hline Finland & 10 & 24 \\
\hline Sweeden & 6 & 25 \\
\hline United Kingdom & 0 & 20 \\
\hline
\end{tabular}

Source: European Commission (2013): "VAT Rates Applied in the Member Statesof the European Union". Situation to 14 January 2014.

In 2012, France and Luxemburg applied a reduced VAT rate to digital books. However, this application of the tax does not comply with the European Directive's decisions in relation to VAT; therefore, the European Commission has requested that these states modify VAT for digital books ${ }^{3}$. In line with the authors' previous interpretation, the Commission takes note of the discrimination that currently exists between digital books and print books, but considers that the measures adopted by the cited jurisdictions give rise to competitiveness problems in detriment to the rest of the states in the Union, an argument which does not prevent the acquisition of digital books from happening in countries with lower taxation.

In short, the reason for the same book paying different taxes, according to the channel of acquisition used for its purchase, can be found in the intangibility of electronic books. That is, it is the medium in which the book is sold that determines the type of VAT to be applied.

\section{THE IMPORTANCE OF ELECTRONIC BOOKS IN THE ECONOMY}

The book or publishing sector forms a significant part of the economy of the different Member States, given that spending in the publishing market is predicted to reach 115,700 million dollars in the year 2016. Within this sector, electronic books acquire a more important role each year, given that a fall in printed books is expected, while e-books continue along the opposite path ${ }^{4}$. Moreover, it is estimated that in 2016, on a world-wide scale,

3 EUROPEAN COMMISSION (2012) “October infringements package: main decisions”, available at: http://europa.eu/rapid/pressrelease_MEMO-12-794_en.htm

${ }^{4}$ An important element to be taken into account when considering the tax treatment of digital books is the role that this medium has in the dissemination of a country's language and culture. In relation to this: Vid. Santos Redondo, M. (2011:153). Available at: http://www.fundacion.telefonica.com/es/arte_cultura/publicaciones/detalle/92. 
electronic books will reach a figure of 20,800 million euros, which is $17.9 \%$ of the publishing market ${ }^{5}$. Furthermore, like other economic sectors that generate wealth for the economy, the publishing sector, firstly generates employment in a direct and indirect way and, secondly, publishing companies face direct taxation, which is a source of revenue for states. In terms of the current economic crisis, this could mean an important source of resources for the public purse.

The analysis of the importance of the publishing sector for the public purse, and more specifically of electronic books, will be carried out, for the Spanish case, in the country where the authors see more statistical data are available, both in quantity and in time span. This situation facilitates, subsequently, the development of an analysis where the importance of public income from electronic books in indirect taxation is made clear. Nevertheless, and given the situation described, the results obtained can be extrapolated to the rest of the European Union states, given that the positive discrimination of traditional books in relation to electronic books is a common factor.

Regulations applicable in each territory must also be taken into account. In Spain, for example, the authors find the restriction of the Fixed Price Law ${ }^{6}$, which does not allow the sale of electronic books at less than 5\% discount in relation to the official selling price. Moreover, the authors must bear in mind the tax policies existing in each territory. Except for countries such as Japan and Korea, other states do not offer a tax reduction for electronic books, something which does occur in the case of printed books ${ }^{7}$.

Consumers of books, in principle, will opt for those with a lower price, independent of the place where the distributing company is located and the indirect tax rate applied. Despite the tax discrimination indicated, a continued growth in the sale of books is observed during recent years, both in the states of the European Union and in Spain. Although the United States is the country where more sales of electronic books take place, $31 \%$ of electronic books are sold there, with, moreover, a very important increase in the sales of electronic books from 2011 to 2012 .

In the case of Spain, Figure 2 shows that the most important growth in electronic books appears in 2007 and continues to grow consistently each year, despite the economic crisis, reaching an ever greater quota of the publishing market.
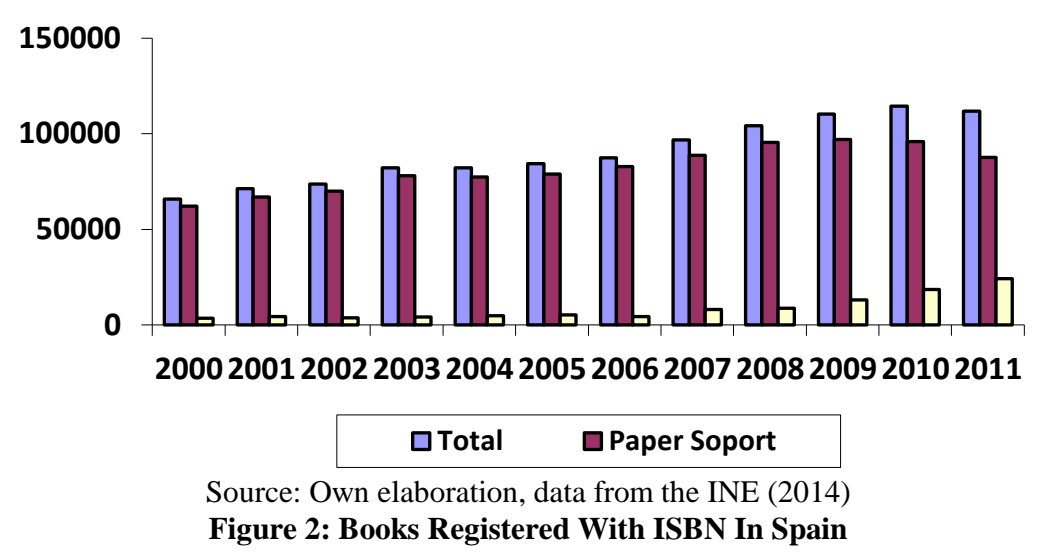

According to the figures of e-book sales, the authors can indicate that the publishing sector, as well as its auxiliary industry, is an important source of revenue for the state coffers. It seems reasonable to presume that the increase of sales is associated with, for example, a growth in the electronic mediums that facilitate reading electronic books, elements which are not subject to a reduced VAT either. Additionally, making electronic books

\footnotetext{
5 PWC (2012): “Global Entertainment and MediaOutlook: 2012-2016”. Available at: http://www.pwc.es/es/publicaciones/entretenimiento-ymedios/assets/global-entertainment-and-media-outlook-2012-2016.pdf Accessed 12 June 2012.

${ }^{6}$ Law 10/2007, 22nd of June, on reading, books, and libraries. Article 9.

${ }^{7}$ ICEX (2012): "Oportunidades de Distribución Digital Internacional para el sector editorial”.
} 
available to the public requires auxiliary companies of elaboration, transformation, commercialization, etc., which could create employment and generate added value for the economy. That is, in the analysis of public revenue originating from electronic books, the authors not only have to bear in mind the issues that affect these in a direct way, but also consider the other branches of the cultural sector that are indirectly involved and which logically also mean an important source of public resources for the state.

In consideration of the fiscal importance of the publishing sector, the authors must take into account an issue of great significance in Spain, digital piracy. Available data show that 12 of every 100 internet users download electronic books in an illegal way, $39 \%$ of which are new publications. Among the reasons found for the illegal downloading of digital contents, $50 \%$ of internet users consider the increase in VAT in Spain to be an important motive $^{8}$.

In Spain, $12.4 \%$ of the total volume of books published are pirated (without taking textbooks into account), which means that a value of 585.6 million euros is not received by publishing companies ${ }^{9}$. This situation has important repercussions for the public purse: firstly, it is a profit that the companies do not receive and, therefore, for which they do not pay taxes; and, secondly, looking at indirect taxation, the illegal downloading of electronic books implies that VAT is not paid either.

\section{CONCLUSIONS}

There are no fiscal arguments that justify the different treatment of the consumption of books in print and electronic formats, beyond the problem of the configuration of the VAT itself, a tax the harmonization of which has not been completed and which still drags with it the problem of taxation at destination or at source. Therefore, this has led to the classification of the delivery of digital goods as services provision, without considering the real nature of the operation. In line with this argumentation, the authors must emphasize that the different tax treatment means altering the decision of the consumer on the basis of tax motives, which is contrary to the objective of fiscal neutrality on which the fiscal system is based.

Despite this penalizing factor, the data on the consumption of digital books grow. As a cause of this, the authors can identify, firstly, the intense rhythm of penetration of information and communication technologies in the society; as the availability of instruments that allow access to electronic books grows, consumption habits reflect this tendency. Secondly, the lower production cost of this intangible good allows for reductions in its price that alleviate the greater tax burden. That is: as the consumer obtains a lower final price, they do not value the tax difference in relation to the printed book. VAT, like any tax on consumption, has the advantage of being a relatively invisible tax of which the political cost of introduction, or increase, is not high. On the other hand, it is a regressive tax that complicates access to taxed goods for those individuals with lower incomes and, which is, moreover, difficult to control if the taxable operations are not declared.

With these elements of analysis, it is not surprising that it is a fertile ground for the proliferation of digital piracy, giving rise to economic problems and, ultimately, to a decrease in states' tax revenue.

Finally, and as a specific recommendation from the authors, the authors estimate that if there are no significant advances in the harmonization of VAT, the Spanish government should opt for the general application of a reduced rate for the cultural sector. Also, regarding the electronic book, it should favor its approximation to the treatment of the print medium, although, on this point, a change in the community's stance is indispensable.

\footnotetext{
${ }^{8}$ GFK (2013): “Observatorio de piratería y hábitos de consumo de contenidos digitales 2012”. Available at: http://www.mcu.es/libro/img/MC/ Observatorio_Pirateria_2012.pdf Accessed 8 July 201.

${ }^{9}$ GFK (2013): “Observatorio de piratería y hábitos de consumo de contenidos digitales 2012”. Available at: http://www.mcu.es/libro/img/MC/ Observatorio_Pirateria_2012.pdf [08/07/2013].
} 


\section{AUTHOR INFORMATION}

Raquel Álamo Cerrillo is Assistant Professor at the University of Castilla-La Mancha (UCLM) with a degree in Business Administration and a $\mathrm{PhD}$ in Public Finance from the same university. The scope of research focuses on the taxation of e-commerce due to the importance that it is acquiring in the economy in recent years. In addition, research tasks of a fiscal nature, both Spanish tax framework as in the European Union, are also developed. The current economic crisis presents an important framework for the analysis of public expenditure and revenue study.

María Gabriela Lagos Rodríguez is Professor at the University of Castilla-La Mancha (UCLM) with a Law Degree and a PhD in Public Finance from the same university. Research carried out focuses on the principle of solidarity as an efficient hub for economic development. National and international taxation, and taxation of electronic commerce, are the other great pillars of study and analysis developed in the research. In the field of public finance, analysis of income and expenditure requires careful study.

\section{REFERENCES}

1. Council Directive 2002/38/EC of 7 May 2002 amending and amending temporarily Directive 77/388/EEC as regards the value added tax arrangements applicable to radio and television broadcasting services and certain electronically supplied services.

2. European Commission (2013): "VAT Rates Applied in the Member Statesof the European Union". Situation to 14 January 2014.

3. European Commission (2012) “October infringements package: main decisions”, available at: http://europa.eu/rapid/press-release_MEMO-12-794_en.htm.

4. GFK (2013): "Observatorio de piratería y hábitos de consumo de contenidos digitales 2012". Available at: http://www.mcu.es/libro/img/MC/Observatorio_Pirateria_2012.pdf Accessed 8 July 201.

5. Icex (2012): "Oportunidades de Distribución Digital Internacional para el sector editorial”.

6. Ine (2014): Instituto de Nacional de Estadistica, available at: http://www.ine.es/.

7. Law 10/2007, 22nd of June, on reading, books, and libraries.

8. PWC (2012): "Global Entertainment and MediaOutlook: 2012-2016”. Available at: http://www.pwc.es/es/publicaciones/entretenimiento-y-medios/assets/global-entertainment-and-mediaoutlook-2012-2016.pdf Accessed 12 June 2012.

9. Santos Redondo (2011): Economía de las insdustrias culturales en España, Ariel. Available at: http://www.fundacion.telefonica.com/es/arte_cultura/publicaciones/detalle/92. 
NOTES 